EO Arquitectos Ltda.

Andrés Link y Jorge Hasbún

Arquitectos Colaboradores Cristián Quijada, Paulina Prat

Colaboración Diseño Industrial Rubén Cohen

Ubicación Salvador 1200, Providencia, Santiaso

Mandante Universidad de Arte, Ciencia y Comunicación (UNIACC)

Materialidad Aluminio, terciado marino, molduras de mañío

Mobiliario Metal pintado al horno y cromado, Sibu, formica color azul,

cuerina color rojo, acero inoxidable

Iluminación Fluorescentes de alta eficiencia y azules, focos PL,

focos dicroicos embutidos

Superficie terreno $1.900 \mathrm{~m}^{2}$

Superficie construida $2.586 \mathrm{~m}^{2}$

Año proyecto 2000

Año construcción 2000-2001

\title{
Cafetería UNIACC
}

Fragmentos y des-lugares

El edificio de la UNIACC, hoy con doce carreras, se formó con la adquisición de diversas propiedades vecinas, lo que trajo como consecuencia una fragmentación espacial que imposibilitaba la lectura de un solo cuerpo, generando la necesidad de entender los fragmentos como pertenecientes a un total.

En este panorama, donde el alumno es el usuario principal de los espacios, se elaboró una propuesta de reacondicionamiento y remodelación espacial del acceso principal, fachadas y cafetería.

Para lograr una lectura unitaria de los fragmentos, se dio un carácter tecnológico a la propuesta general, mediante intervenciones puntuales y continuas.

Dentro de estas intervenciones, en la cafetería se desarrolla la combinatoria de cuatro relaciones espaciales atípicas para un lugar de este tipo, y basadas en el uso que el alumnado daría al recinto: las condiciones de permanencia, la libre combinatoria de la relación intermedia y grupal, de estudio, el uso personal e individual en la barra y el espacio deambulatorio y funcional de la circulación y el comedor.

La propuesta logró integrar estas condiciones, desarrollando una ambientación de mobiliario y espacialidad que plasmaría un lugar donde el alumno, el usuario principal, se interrelacionaría en los distintos espacios así concebidos.

"La arquitectura es un total, por lo tanto es fundamental identificar sus fragmentos" (Rem Koolhaas)

\section{Andrés Link}

Arquitecto, Universidad de Chile, 1998

Jorge Hasbún

Arquitecto, Universidad de Chile, 1999. Paralelamente al ejercicio profesional independiente, es ayudante de la cátedra de Taller de Diseño Arquitectónico de $2^{\circ}$ año en la Facultad de Arquitectura y Urbanismo de la Universidad de Chile.
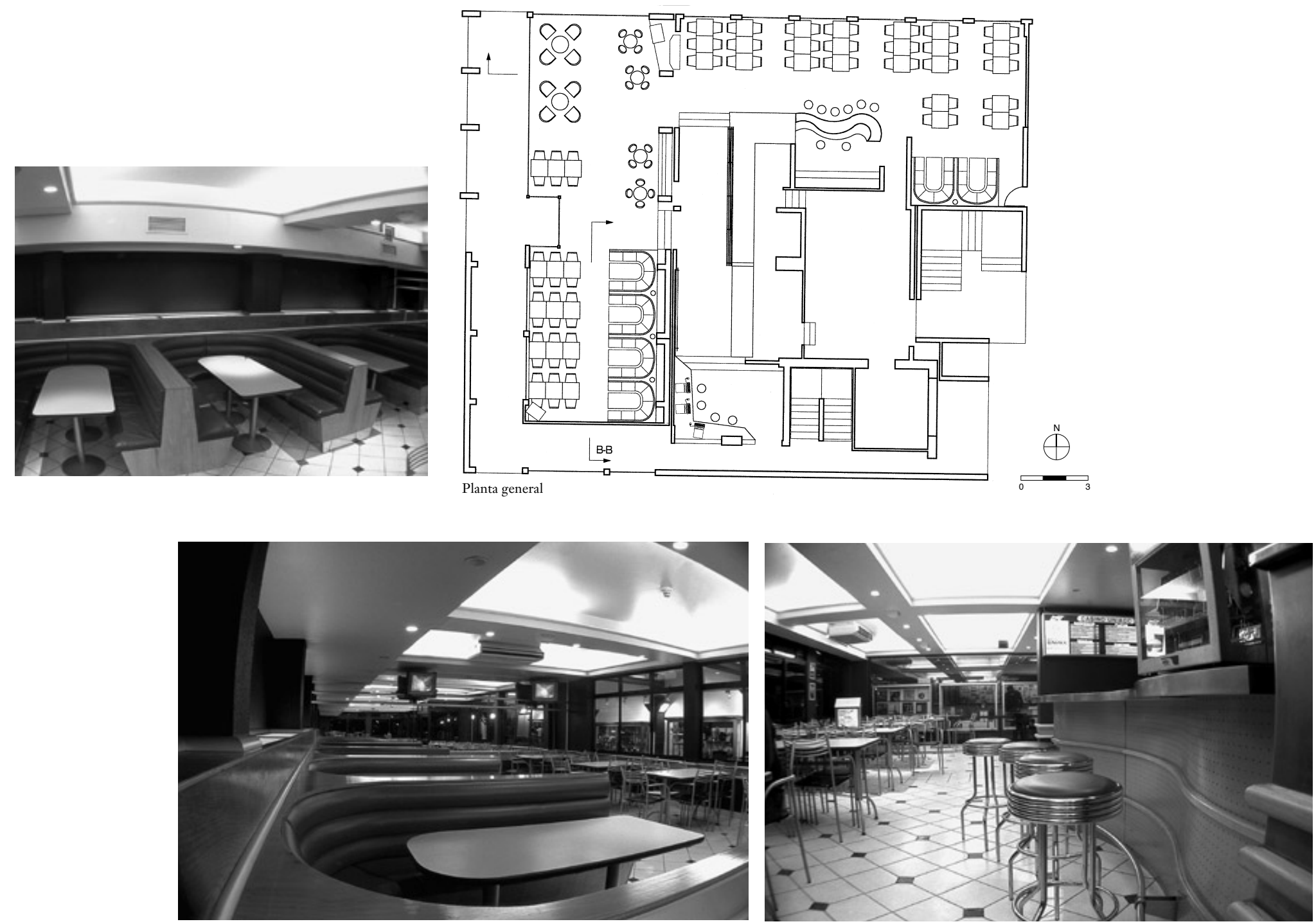